
\title{
Seguimento do perfil do solo no corte e/ou levantamento de produtos agrícolas rasteiros
}

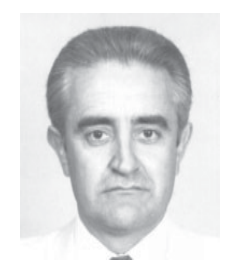

Oscar A. Braunbeck ${ }^{1}$ \& Paulo S. G. Magalhães ${ }^{2}$

\author{
1 FEAGRI/UNICAMP. Fone: (19) 3788-1049. E-mail: oscar@agr.unicamp.br (Foto) \\ 2 FEAGRI/UNICAMP. Fone: (19) 3788-1053. E-mail: paulo@agr.unicamp.br
}

Protocolo 050 - 18/4/2001

\begin{abstract}
Resumo: Durante a colheita ou o carregamento de produtos rasteiros como feijão, cana-deaçúcar e alguns produtos hortícolas, torna-se necessário seguir com precisão o perfil do solo sem que os garfos levantadores se afastem nem penetrem no solo, para evitar perdas no primeiro caso ou contaminação do produto com sílica e bactérias, no segundo caso. O seguimento do perfil poderá ser feito por mecanismos ativos ou passivos, cujos cortadores ou levantadores possam ser sustentados por barras articuladas com centros instantâneos de rotação virtual ou real, de cuja localização depende o desempenho de flutuação o qual, por sua vez, depende também da localização do ponto de referência utilizado para o controle de altura, que deve estar próximo do ponto de levantamento ou corte do produto. Os casos particulares de uma ponteira articulada utilizada na barra de corte das colhedoras combinadas e do cortador de disco duplo das colhedoras Australianas de cana-de-acúcar, são analisados. Formas alternativas de se melhorar o desempenho de seguimento do perfil do solo são apresentadas, incluindo resultados para mecanismos passivos de pequena e grande massa, assim como um mecanismo ativo que utiliza modelos dinâmicos da plataforma para efetuar o controle retroalimentado de posição.
\end{abstract}

Palavras-chave: colheita, carregamento, varredura do solo, mecanismos, controle

\section{Contouring the soil surface during cutting and/or lifting of agricultural products}

\begin{abstract}
Harvesting and loading of products, such as beans, sugarcane and some horticultural ones require a precise ground contouring process. Lifting forks should neither get away from the ground surface nor penetrate into it in order to avoid losses in the first case or product contamination with silt or soil bacteria in the second case. Active or passive mechanisms can be used to follow the ground profile. Lifting or cutting devices can be mounted on linkages having instant rotation centers adequately located for optimum flotation performance. The reference point of the ground following process should be close enough to the lifting or cutting point to avoid position errors resulting from ground surface unevenness. The main limitations of the articulated fork of the combine sickle bar and the double disk base cutter of the Australian sugarcane harvesters are discussed and alternative solutions are proposed to improve ground following performance. Research results of passive mechanisms having low and high mass are discussed together with an active control system for a combine header.
\end{abstract}

Key words: harvesting, loading, ground sweeping, mechanisms, control

\section{INTRODUÇÃO}

Certos produtos agrícolas, como colmos inteiros de canade-açúcar, vagens de algumas cultivares de feijoeiro ou soja, tomate para processamento industrial e outros produtos hortícolas, se apresentam, no momento da colheita, encostados ou muito próximos da superfície do solo. Esta condição promove perdas do produto e de sua qualidade pela contaminação com terra e microrganismos do solo, além de aumentar o custo do processamento industrial.

No caso das usinas de açúcar e álcool, a contaminação gera redução nas eficiências de filtragem e clarificação do caldo, eficiências essas ligadas à qualidade final do açúcar, Ridge \& Dick (1992) e também implica no uso de um número maior de equipamentos, por exemplo, na lavagem de colmos inteiros, em que são necessárias esteiras inclinadas, bombeamentos e estruturas de tratamento para a aplicação de 6 a $8 \mathrm{~m}^{3}$ de água por tonelada de colmo. A lavagem, além de ter maior custo econômico, provoca um custo ambiental atualmente inaceitável. É importante lembrar que os referidos problemas de contaminação foram conseqüência da introdução do corte ou do carregamento mecanizado onde se passou de um mecanismo preciso e sofisticado, como é a mão do homem, para mecanismos grosseiros, como garras hidráulicas e discos rígidos de corte. É 
coerente considerar-se que os recursos atuais da engenharia podem gerar soluções mecânicas mais eficientes que os atuais mecanismos, embora não atinjam a sofisticação da mão do homem. Neste pensamento se inserem os objetivos deste trabalho.

Esforços importantes baseiam os programas de melhoramento genético para elevar a altura de inserção das vagens, no caso da soja, ou obter variedades de porte ereto, no caso da cana-de-açúcar; isto gera restrições nos programas de melhoramento que os desviam dos objetivos economicamente mais importantes, como produtividade e resistência a pragas e doenças, os quais só podem ser abordados através do melhoramento genético.

Os princípios mecânicos utilizados atualmente para $o$ levantamento de soja, feijão, cana-de-açúcar ou capim, têm permanecido quase inalterados desde sua proposta original, apesar da evolução significativa experimentada pela eletrônica e pelos recursos informatizados de projeto mecânico, através de simulação e otimização.

Este artigo analisa os princípios de alguns mecanismos utilizados atualmente e suas limitações para o corte e/ou levantamento, associadas a perdas, contaminação, demanda de potência e desgaste dos órgãos ativos de corte. O trabalho descreve algumas propostas em estudo e os recursos científicos utilizados para se conseguir maior continuidade no seguimento do perfil do solo, ou seja, uma varredura melhor da superfície do terreno.

\section{PRINCÍPIOS DE LEVANTAMENTO}

O levantamento de produtos rasteiros implica na aplicação de forças verticais ascendentes de magnitude suficiente para afastar o produto da superfície do solo, sem danificá-lo e sem contaminá-lo pela incorporação de terra.

A força de levantamento pode ser aplicada pneumática ou mecanicamente, através de um garfo, que gera um efeito cunha entre o solo e o produto. O princípio pneumático é utilizado comercialmente para o levantamento de partículas pequenas, soltas e numerosas, como grãos de café e sementes de pastagens. Este princípio demanda equipamentos dotados de ventiladores e recolhe o produto com alta concentração de impurezas, compostas de solo e restos vegetais. O levantamento mecânico pelo efeito cunha requer atenção especial com relação à sua capacidade de seguimento do perfil do solo (microrrelevo) para que o levantamento ou corte do produto se processe sem perdas ou contaminação excessiva.

\section{Levantamento pelo efeito cunha}

O efeito cunha, ilustrado qualitativamente na Figura 1, surge quando um garfo em movimento atinge um produto apoiado na superfície do solo. Esta interação desenvolve uma força $F_{i}$ entre o garfo e o produto, a qual equilibra o peso do produto $\mathrm{P}$ através de sua componente vertical $F_{v}$ viabilizando, assim, o movimento ascendente do produto. Para os fins desta análise qualitativa não foi considerada a força de atrito entre o produto e o garfo.

A força de interação $F_{i}$ apresenta, também, uma componente horizontal $\mathrm{F}_{\mathrm{h}}$, indesejável, que pode ser equilibrada pela reação $\mathrm{R}_{\mathrm{p}}$ das plantas ou outras peças do produto a serem colhidas na seqüência ou, ainda, por um mecanismo específico, como é o

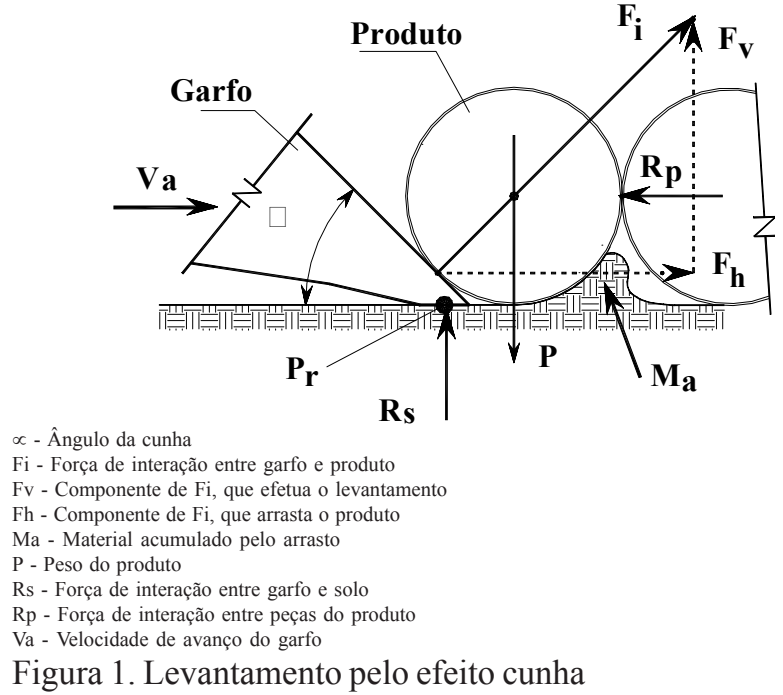

caso do molinete com dedos móveis das colhedoras de cereais. Caso nenhum desses recursos esteja disponível, ocorre o arrastamento do produto sobre a superfície do solo, até se desenvolver uma reação pelo acúmulo de material, Ma. Esta condição é indesejável pela contaminação que provoca no produto, principalmente sob condições de solo úmido ou pouco agregado. Por simples observação da Figura 1, pode-se concluir que este princípio mecânico de levantamento requer que o ângulo $\propto$ do garfo seja mínimo para reduzir a componente de força indesejável $\mathrm{F}_{\mathrm{h}}$, e que a ponta do garfo atinja o produto na sua metade inferior, para evitar que o mesmo seja rejeitado no lugar de colhido. Esta última condição requer que o extremo do garfo faça um seguimento preciso da superfície do solo, sem penetração ou afastamento da mesma. Este comportamento representa o ponto central do processo de seguimento discutido neste trabalho.

\section{Ponto de referência para o seguimento do perfil}

Para o seguimento do perfil do solo podem ser usados mecanismos ativos ou passivos, que sofrem um reposicionamento contínuo com relação ao solo, de acordo com um ponto de referência sobre seu perfil; esse ponto deve estar localizado próximo ao local do levantamento ou corte, para evitar que o processo de seguimento seja prejudicado pelas irregularidades do terreno. No caso ilustrado na Figura 1, o ponto de referência, $\mathrm{P}_{\mathrm{r}}$, encontra-se na posição ideal, ou seja, muito próximo do ponto de contato entre o garfo e o produto, onde se inicia o levantamento. A Figura 2 ilustra o caso do controle ativo da altura de corte basal de uma colhedora de cana-de-açúcar, em que o ponto de corte $\mathrm{C}$ e o ponto de referência, $\mathrm{P}_{\mathrm{r}}$, encontram-se afastados mais de $0,5 \mathrm{~m}$; esta condição promove perdas de matéria-prima na forma de tocos com altura $\mathrm{H}_{\mathrm{c}}$, ou contaminação da matéria-prima com terra, quando o disco opera em profundidade. No caso das colhedoras de cereais, a distância entre os pontos de referência para o controle da altura e os garfos centrais da barra de corte da plataforma, podem superar os $4 \mathrm{~m}$.

Para melhorar o desempenho de seguimento do perfil do solo, as colhedoras combinadas utilizam ponteiras articuladas, como a ilustrada na Figura 3. O princípio de operação da ponteira articulada exige que a altura $\mathrm{H}$ da barra de corte seja muito 


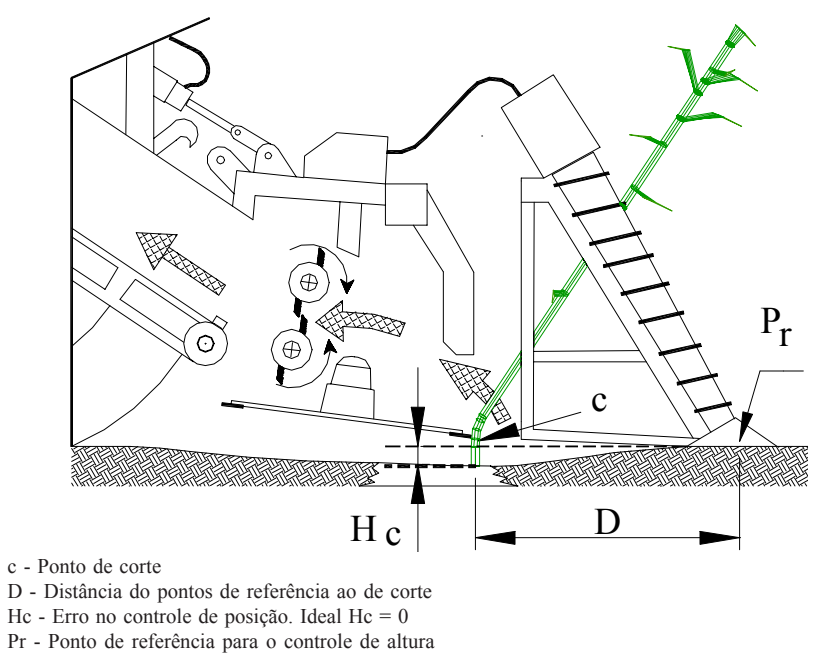

Figura 2. Ponto de referência, Pr, para o controle ativo do seguidor de perfil

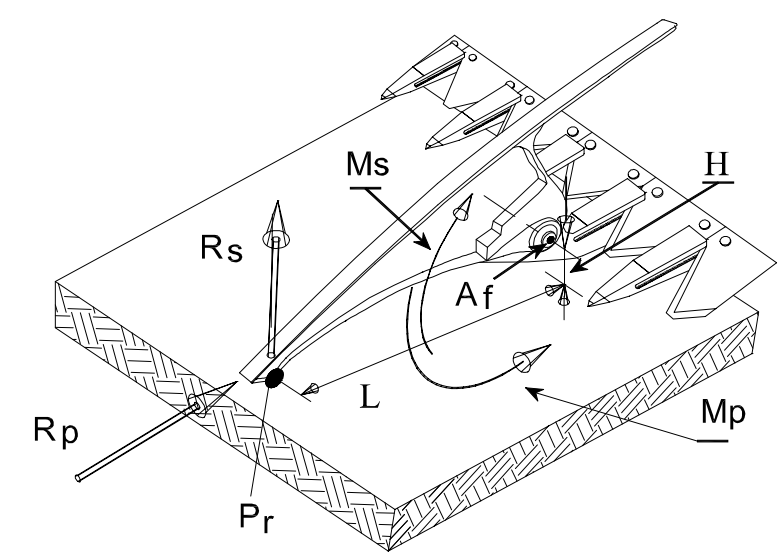

H - Altura da articulação da ponteira

L - Distância da articulação ao ponto de referência.

Mp - Momento da força Rp

Ms - Momento da reação do solo Rs

$\mathrm{Pr}$ - Ponto de referência

$\mathrm{Rp}$ - Ação das plantas sobre a ponteira

Rs - Reação do solo sobre a ponteira

Figura 3. Ponteira articulada para barra de corte alternativo

inferior ao comprimento $\mathrm{L}$ da ponteira; desta forma, consegue-se um comportamento de flutuação satisfatório sobre o perfil; por outro lado, o seguimento do perfil (flutuação) depende do equilíbrio de momentos, descrito a seguir: a força longitudinal

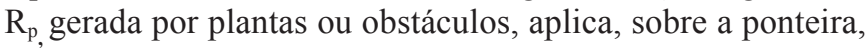
um momento de valor $\mathrm{M}_{\mathrm{p}}$, dado pela Eq. (1). Este momento atua no sentido anti-horário, com tendência a afundar a ponteira no solo.

$$
\mathrm{M}_{\mathrm{p}}=\mathrm{R}_{\mathrm{p}} \mathrm{H}
$$

Como resultado da ação $\mathrm{M}_{\mathrm{p}}$, surge a reação vertical do solo $\mathrm{R}_{\mathrm{s}}$, que aplica, sobre a ponteira, um momento de sentido horário, $\mathrm{M}_{\mathrm{s}}$, cujo valor é dado pela Eq. (2).

$$
\mathrm{M}_{\mathrm{s}}=\mathrm{R}_{\mathrm{s}} \mathrm{L}
$$

Igualando-se os dois momentos, surge o valor de $\mathrm{R}_{\mathrm{s}}$, dado pela Eq. (3), o qual deve ser suficientemente pequeno para viabilizar a flutuação do garfo sobre solos com baixa agregação, ainda que o mesmo deva superar obstáculos que elevem significativamente o valor de $R_{p}$.

$$
\mathrm{R}_{\mathrm{s}}=\mathrm{R}_{\mathrm{p}} \mathrm{H} / \mathrm{L}
$$

A robustez do processo de flutuação do garfo demanda um valor baixo da relação $\mathrm{H} / \mathrm{L}$, o que obriga às colhedoras a operarem com a barra de corte muito próximo ao solo, gerando interferência com o mesmo e até captação de terra pela plataforma, o que contamina o produto, como acontece na colheita do feijão. Uma forma de se contornar esta limitação, é através da utilização de mecanismos articulados, por exemplo pantográficos, em que o garfo gira em torno de um centro instantâneo ou articulação virtual que poderá estar localizada no caminho de fluxo do produto ou no subsolo, permitindo dimensionar-se as distâncias L e H com base apenas nas exigências do processo de flutuação do garfo, sem preocupação com relação a interferências da articulação física com o solo ou o produto.

Como ilustração observa-se, na Figura 4, um rastelo amontoador utilizado em carregadoras de cana-de-açúcar. Os garfos flutuantes (1) sustentados por mecanismos de quatro barras, giram instantaneamente em torno de articulações virtuais, $\mathrm{A}_{\mathrm{v}}$, localizadas no subsolo a uma profundidade $\mathrm{H}$; nesta configuração, tanto a reação vertical ascendente $\mathrm{R}_{\mathrm{s}}$ aplicada pelo solo sobre a roda (2) quanto a ação horizontal da leira de cana ou de qualquer obstáculo $R_{p}$, atuam no sentido de retirar o garfo do solo, ou seja, o sistema reage com segurança na presença de sobrecargas provocadas por obstáculos, como pedras ou camalhões. Um mecanismo biela manivela retira continuamente a carga de colmos do topo do garfo, na direção (7) despejando o material no topo da leira (8); esta ação visa manter a reação $R_{s} \mathrm{em}$ valores baixos, compatíveis com solos de baixa sustentação. O desempenho de flutuação ou seguimento do perfil desse mecanismo surge como conseqüência dos baixos valores de $\mathrm{R}_{s}$, sem atingir valores nulos, combinado com um comportamento seguro na presença de sobrecargas.

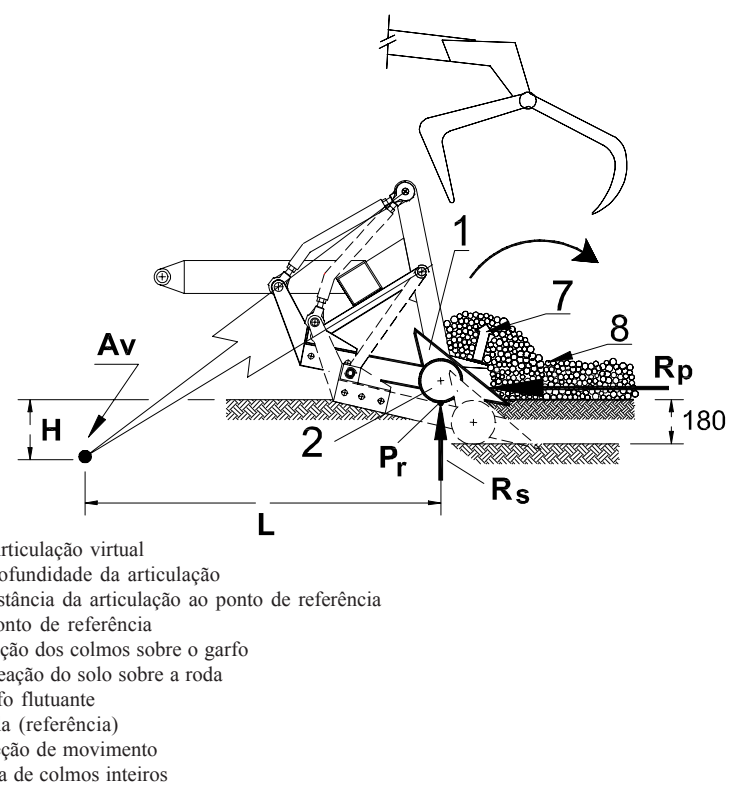

Figura 4. Rastelo amontoador para carregamento de colmos inteiros de cana-de-açúcar

\section{Corte basal de cana-de-açúcar}

O cortador de disco duplo convencional, utilizado para o corte de base nas colhedoras de cana-de-açúcar em rebolos, correntemente denominadas colhedoras de cana picada, é 
ilustrado na Figura 5, a qual, juntamente com a Figura 6 e a descrição a seguir, pretende facilitar a interpretação da informação contida nos artigos discutidos posteriormente. $\mathrm{O}$ desempenho de varredura do cortador de base das colhedoras de cana-de-açúcar existentes, é insatisfatório. O ajuste da altura de corte das mesmas representa um compromisso entre a qualidade e as perdas da matéria-prima.

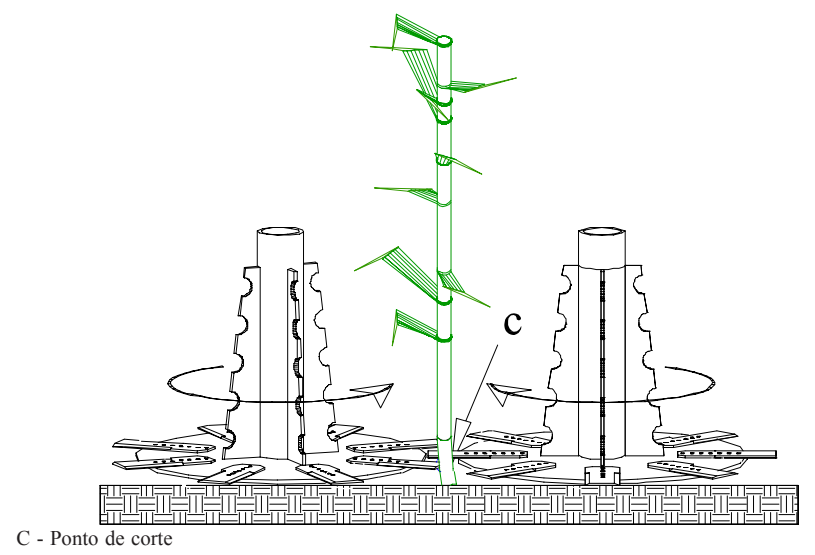

Figura 5. Cortador de disco duplo para efetuar o corte de base e a varredura do solo na colheita de cana-de-açúcar

A.

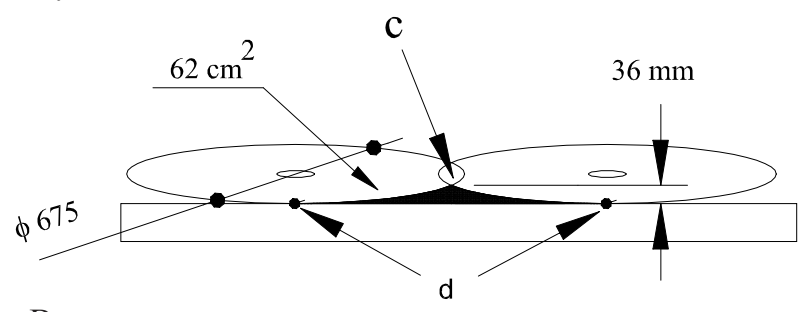

B.

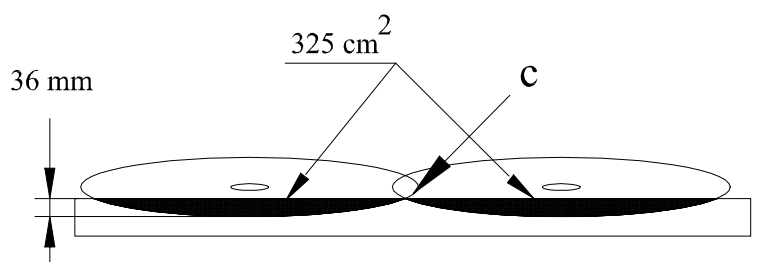

a) Evitando contaminação

b) Evitando perdas

c) Ponto de corte

d) Ponto de tangência com a superficie do solo

Figura 6. Vista em elevação da trajetória periférica das facas do cortador de disco duplo para dois modos de operação

Os discos do referido cortador giram em sentidos opostos e são montados com inclinação longitudinal perto de $10^{\circ}$; o corte da linha de cana processa-se na faixa central de encontro dos discos. Normalmente, para reduzir as perdas torna-se necessário operar o cortador de base em profundidade, como alternativa a um recurso de varredura mais eficiente. Esta condição promove a incorporação de um alto volume de solo aos colmos colhidos.

\section{Qualidade e perdas de matéria-prima no corte basal de cana- de-açúcar}

O cortador de disco duplo pode ser operado em uma de duas condições que levam a resultados antagônicos:
Evitar contaminação da matéria-prima com terra: Condição ilustrada na Figura 6A para discos com diâmetro de $675 \mathrm{~mm}$ na trajetória do ponto cortante externo das facas. Nesta configuração, o ponto "c" de corte encontra-se $36 \mathrm{~mm}$ acima da superfície do solo. O extremo frontal da linha de corte das facas opera rente ao solo nos pontos "d", sem penetração. Esta condição gera, entre os discos e a superfície plana do solo, uma janela com área projetada num plano vertical de $62 \mathrm{~cm}^{2}$. Nesta janela não existe varredura e, conseqüentemente permite a perda de colmos inteiros e fragmentos, além de tocos resultantes do corte elevado. A referida condição agrava-se no caso de existir alguma depressão (sulco) na linha de plantio, situação esta bastante freqüente.

Evitar perdas de matéria-prima: Condição ilustrada na Figura 6B. Aqui, o ponto "c" de corte encontra-se rente à superfície do solo. Os discos operam em profundidade, cortando $216 \mathrm{~m}^{3}$ de solo por hectare, como conseqüência da movimentação de uma seção transversal de solo de $325 \mathrm{~cm}^{2}$ para um comprimento de linha de $6.666 \mathrm{~m} \mathrm{ha}^{-1}$, correspondente a um espaçamento de plantio de 1,5 m. Considerando-se que o corte inercial dos colmos requer uma velocidade tangencial das facas na faixa de $20-25 \mathrm{~m} \mathrm{~s}^{-1}$, a referida operação em profundidade resulta em desgaste acelerado das facas e demanda de potência muitas vezes superior à estritamente necessária para o corte dos colmos.

As impurezas minerais incorporadas pelos discos do cortador de base foram quantificadas por Henkel et al. (1979). Os testes foram realizados com uma colhedora Toft-6000, em canaviais com colmos eretos e deitados, com solos úmidos e secos. A altura de corte foi ajustada aos níveis de $50 \mathrm{~mm}$ acima da superfície do solo, rente ao solo, e $50 \mathrm{~mm}$ abaixo da sua superfície.

As canas colhidas com discos operando a $50 \mathrm{~mm}$ de profundidade apresentaram teor de terra superior a $5 \%$, nos casos de solo úmido, ou em canas deitadas. Operando os discos rentes ao solo, nas mesmas condições de cana e solo, os teores de terra foram pouco superiores a $0,5 \%$. Nos casos de canas eretas, com solos secos e operação rente ao solo, os autores observaram teores de terra próximos de $0,25 \%$.

Ridge \& Dick (1998) avaliaram a capacidade de rejeição de terra dos cortadores de disco convencionais, quando submetidos, em bancada de ensaio, a vazões de terra equivalentes à operação de campo com profundidades de 25 e $50 \mathrm{~mm}$. Apesar do cortador de base ter rejeitado entre 83 e 93\% da terra e os rolos alimentadores recusado de 3 a $16 \%$ da mesma, o teor final de terra na matéria-prima permaneceu em torno de $1,5 \%$. Os mesmos autores testaram, também, o cortador com suporte de facas aberto, tipo "spider" (aranha ou pé-de-galinha) como recurso para reduzir o teor de terra na matéria-prima. Os resultados desta alteração não foram conclusivos, mas os resultados desta pesquisa apontam no sentido da conveniência de se evitar a contaminação, já que a posterior retirada da mesma é difícil.

Segundo Ridge (1990) para minimizar a presença de solo na matéria-prima são necessárias alterações nas práticas culturais existentes (preparo do solo, plantio, espaçamento de plantios e outras) ou mudanças no projeto do disco cortador basal. O autor destaca os fatores relacionados ao corte basal que contribuem para elevar os níveis de contaminação da matéria-prima, 
que são: movimentação de solo provocada pelas sapatas dos levantadores helicoidais (pirulitos), excessivo ângulo dos colmos, promovido pelo anteparo localizado antes do corte basal, e excessivo fluxo de solo, promovido pelo cortador basal, quando o corte é realizado abaixo do nível do solo. Analisando-se a evolução da contaminação dos colmos com terra, no período de existência do sistema Australiano de colheita, observa-se que o teor de terra na matéria-prima aumentou com a implantação da colheita de cana picada e, ainda, que o problema está associado principalmente ao princípio operacional utilizado para o corte basal, sem evidências que indiquem que este poderá ser corrigido através de aprimoramentos periféricos do equipamento.

Ridge \& Dick (1992) correlacionaram os teores de terra registrados nas indústrias do estado de Queensland, na Austrália, no período de 1960 a 1989, o qual corresponde à passagem da colheita de cana inteira, com carregamento mecânico, para a colheita de cana picada nesse país. A correlação mostra um aumento continuamente crescente, de 12 para $16 \mathrm{~kg} \mathrm{t}^{-1}$, no período. Os autores continuam a reiterar recomendações feitas em pesquisas anteriores sobre mudanças nas práticas agronômicas e sobre alguns parâmetros de projeto da colhedora, já descritos no trabalho de Ridge (1990). Duas observações importantes podem ser feitas com base nesses resultados: 1) os teores de impureza mineral foram sempre crescentes no período, sem indicação de queda, como resultado de mudanças nas práticas agronômicas ou na forma de utilização das colhedoras; 2) as impurezas minerais aumentaram aproximadamente $0,4 \%$ com a passagem do sistema de cana inteira para a cana picada, sendo que esta última deve ser processada sem lavagem, em função das elevadas perdas de açúcar, que sofrem os rebolos em contato com a água.

Após aproximadamente quatro décadas, pode-se observar, com bastante clareza, que existem limitações intrínsecas no princípio operacional do cortador de discos rígidos, que impedem a redução dos níveis de contaminação abaixo dos atualmente praticados. Pode-se concluir, também com bastante segurança, que novos esforços devem ser concentrados em mecanismos alternativos que evitem a captação dessas impurezas, no lugar de tentar retirá-las após sua incorporação à matéria-prima.

São necessárias, portanto, alterações nos referidos princípios, que ataquem especificamente os problemas de contaminação e perdas, e não apenas mudanças na operação dos equipamentos existentes ou na sistematização dos terrenos (Braunbeck et al., 1999 e Braunbeck, 1999).

\section{Impacto econômico do corte basal}

Henkel et al. (1979) verificaram que a operação do cortador de base em profundidade reduz significativamente as perdas de matéria-prima, em particular nos casos de canas deitadas e, também, que esse ganho não compensou, economicamente, a perda de qualidade provocada pelo maior teor de impurezas minerais incorporadas aos colmos, de acordo com as regras de pagamento da matéria-prima, pelo teor de sacarose, aplicadas na Austrália. De acordo com esta pesquisa, dever-se-ia optar pela condição de operação rente ao solo (Fig. 6A) ainda que com perdas superiores.
Deve-se destacar que as perdas totais, incluindo-se perdas visíveis e invisíveis, oscilam entre 7 e $15 \%$. Considerando-se, dentro dessa faixa, uma perda de $10 \%$ e, também, que o custo de produção da tonelada de cana-de-açúcar é de aproximadamente US\$10,00 (Nunes, 2000) dever-se-ia imputar, à colheita mecânica, um custo adicional de US\$ 1,00 $\mathrm{t}^{-1}$. Este procedimento não é praticado, visto que não existe alternativa de colheita mais eficiente, que permita cotejar custos. $O$ fato de não incidir custo de transporte sobre a matéria-prima perdida introduz certo erro nas estimativas, o que não altera o conceito nem a ordem de magnitude dos números. Uma varredura eficiente da superfície do solo poderia reduzir significativamente essas perdas, mantendo a qualidade e podendo efetuar reduções drásticas da potência de acionamento.

Ridge \& Dick (1988) consideram que o processamento da cana com terra gera um custo adicional na indústria em dólar australiano (\$A) de 0,62 a 0,95 $\mathrm{t}^{-1}$ de cana processada, e verificaram que o teor de impurezas da matéria-prima destinada à indústria, depende do teor de folhas e do diâmetro dos colmos, o que torna certas variedades de diâmetro pequeno e alto teor de folhas inadequadas à colheita mecânica sem queima prévia, diminuindo assim o aproveitamento dos resultados dos programas de melhoramento.

\section{Demanda de potência para o corte basal}

A força necessária para o corte de um colmo de cana-deaçúcar, foi quantificada por Kroes \& Harris(1996); a pesquisa registrou uma energia de $13 \mathrm{~J}$ para o corte de um colmo, o que demandaria uma potência de $390 \mathrm{~J} \mathrm{~s}^{-1}(390 \mathrm{~W})$ para cortar, em condições de colheita, 15 colmos $\mathrm{m}^{-1}$ com velocidade de deslocamento de $2 \mathrm{~m} \mathrm{~s}^{-1}$. Potências superiores a $75 \mathrm{KW}$ são instaladas nos cortadores de base das colhedoras comerciais através de bombas hidráulicas com vazão de aproximadamente $5 \mathrm{~L} \mathrm{~s}^{-1} \mathrm{e}$ válvulas de alívio ajustadas em $17 \mathrm{MPa}$. Embora no circuito hidráulico existam outras funções de menor demanda de potência, em série com o motor-divisor de fluxo do cortador de base, pode-se estimar que mais de $50 \%$ dessa potência instalada se destinam ao corte de base e, conseqüentemente ela é utilizada para o corte e movimentação do solo. Duas considerações importantes podem ser feitas com base nos resultados da referida pesquisa de Kroes \& Harris: 1) os trabalhos orientados à redução da força e da energia de corte, otimizando ângulos, materiais ou espessura das facas, têm impacto desprezível na demanda total de potência do cortador; 2) existe um potencial importante de redução de investimento e custo operacional das colhedoras, se a potência instalada para o corte de base, em termos de motor de combustão interna e componentes hidráulicos como bombas, motores, válvulas, tubulações reservatórios e filtros, for dividida por um fator de 10 ou 20, através de uma tecnologia de seguimento ou varredura do perfil que evite a penetração das facas no solo .

\section{SEGUIMENTO DO SOLO NA COLHEITA DO FEIJOEIRO}

As limitações das tecnologias atualmente disponíveis para o seguimento do perfil do solo, apresentam-se também na colheita do feijoeiro; o uso das colhedoras combinadas convencionais exige que diversos fatores relacionados ao tipo 
de planta e ao sistema de cultivo, se adequem ao equipamento. É necessário que o feijoeiro apresente porte ereto, resistência estrutural que evite o acamamento, maturação uniforme, resistência a deiscência e altura suficiente na inserção da primeira vagem, Embrapa (1985). Outros autores também ressaltam a necessidade de adaptação da planta à máquina. Lollato (1989) considera que um dos fatores mais importantes a serem considerados para a adaptação do feijoeiro aos equipamentos existentes, é a escolha da cultivar, que deve apresentar porte ereto, alto e com ângulo agudo de ramificação, ponto de inserção das primeiras vagens elevado, maturação suficientemente uniforme e resistência ao acamamento. Essas exigências desviam os programas de melhoramento de objetivos economicamente mais importantes, como aumento de produtividade e resistência a pragas e doenças.

\section{Ajuste de posição para o seguimento do perfil do solo}

O seguimento do perfil do solo implica no reposicionamento contínuo do mecanismo ao longo dos sucessivos pontos do perfil. A massa do referido mecanismo varia de acordo com sua função; no caso do cortador de base das colhedoras de canade-açúcar, ilustrado na Figura 5, esta é de aproximadamente 400 kg; no entanto, a massa da ponteira articulada da Figura 3, é de aproximadamente $2 \mathrm{~kg}$. De acordo com o perfil do solo e a massa do mecanismo seguidor, poder-se-á utilizar recursos de seguimento ativos ou passivos, cujas características de projeto, construção, manutenção e custo, diferem significativamente. No caso do seguimento passivo não é alimentada energia hidráulica nem elétrica ao mecanismo, para sua movimentação no processo de seguimento; o mecanismo é posicionado nos movimentos ascendentes, pela força de reação do solo e nos movimentos descendentes, pela ação do peso próprio do mecanismo e do produto; as Figuras 3 e 4 representam casos de seguimento passivo.

O seguimento ativo utiliza fonte de potência auxiliar, normalmente hidráulica, para efetuar o posicionamento do mecanismo. O controle do posicionamento ativo pode ser do tipo liga-desliga, no qual a força ou velocidade de correção independe da magnitude do erro de posição a ser corrigido ou das características dinâmicas do mecanismo a movimentar. Uma alternativa de seguimento ativo mais precisa, consegue-se quando o circuito de controle retroalimentado aplica uma ação corretiva, cuja magnitude depende da magnitude do erro e utiliza um modelo paramétrico do comportamento dinâmico do mecanismo, para minimizar o erro de seguimento.

\section{Seguimento ativo com controle retroalimentado}

As colhedoras combinadas equipadas com controle automático de altura utilizam o sistema de controle liga-desliga, o qual, apesar da simplicidade e do baixo custo, não apresenta bom desempenho de seguimento do perfil em solos irregulares (Lopes, 1999) o mesmo autor pesquisou, como alternativa, para conseguir melhor desempenho de seguimento, um sistema de controle retroalimentado, através de um modelo de laboratório em escala. O modelo utiliza uma sapata articulada para detectar o perfil do solo e estimar o erro de seguimento. Um potenciômetro acoplado à sapata fornece o sinal elétrico de erro, o qual é microprocessado em um algoritmo de controle para gerar o sinal que é enviado à válvula hidráulica de controle de pressão; esta válvula aplica os valores de pressão necessários em cada face do cilindro hidráulico para efetuar a correção de altura de corte.

O trabalho simulou o comportamento dinâmico da plataforma, com base na resposta de freqüência, no intervalo de 0,1 a $5 \mathrm{~Hz}$, utilizando-se três modelos, sendo dois empíricos, baseados em estimação de parâmetros, e um modelo analítico, com base na mecânica de Newton. Um dos modelos utiliza os sinais de entrada e saída no domínio do tempo, para estimar os parâmetros da função de transferência da unidade, e o segundo ajusta a função resposta de freqüência, utilizando dados experimentais através do método dos mínimos quadrados. $\mathrm{O}$ autor compara o desempenho dos referidos modelos e do modelo analítico utilizando diagramas de Bode, juntamente com perturbações do tipo senoidal e onda quadrada. Os modelos empíricos apresentaram resultados satisfatórios e o modelo analítico apresentou desvio nos ângulos de fase, para as baixas freqüências. O modelo analítico no entanto, mostrou vantagens na geração de alguns parâmetros utilizados nos modelos empíricos.

\section{Seguimento passivo com mecanismo articulado de pequena massa}

Murcia (1997) sustentou a tese de que mecanismos articulados de quatro barras, com pouca massa e adequadamente dimensionados, utilizando-se recursos de otimização, podem acompanhar o perfil do terreno sem afastamento nem afundamento, de forma a se evitar perdas ou movimentação do solo, que possam prejudicar o mecanismo ou o produto; a proposta visa substituir a articulação fixa da ponteira da Figura 3 por um centro instantâneo virtual gerado por um mecanismo de quatro barras e localizado abaixo do nível do solo. $\mathrm{O}$ autor fundamenta o trabalho pela necessidade de se desenvolver recursos para elevar vagens e ramos de soja localizadas, total ou parcialmente, abaixo da linha de corte da plataforma; o autor utiliza um modelo dinâmico do mecanismo, desenvolvido com auxílio do método de Lagrange, para obter a força de interação entre o perfil e o garfo levantador, o qual foi validado experimentalmente, utilizando-se excitação senoidal, tipo deslocamento.

O valor da força foi minimizado de 20,5 para $8,9 \mathrm{~N}$, alterando-se o comprimento das barras e a constante elástica da mola. Não houve interrupção no seguimento de solo, com velocidade de deslocamento de $1,6 \mathrm{~m} \mathrm{~s}^{-1}$.

\section{Seguimento passivo com mecanismo articulado de grande massa}

Volpato (2001) modelou, simulou e otimizou, virtualmente, um mecanismo pantográfico para seguimento do solo, com massa de $397 \mathrm{~kg}$, que suporta uma unidade piloto para corte basal de cana-de-açúcar; este cortador foi posteriormente construído e avaliado em caixa de solo. O desempenho do modelo virtual e do mecanismo experimental foi satisfatoriamente próximo quando trafegando perfis senoidais com amplitudes de 25 e $50 \mathrm{~mm}$, para um período linear (distância entre sulcos) de 1,23 m; as velocidades de avanço variaram entre 0,69 a 2,12 $\mathrm{m} \mathrm{s}^{-1}$.

O mecanismo existente (experimental) foi inicialmente otimizado pelo referido autor que considerou como variáveis de projeto, o comprimento das barras e a constante da mola, 
cujo comprimento foi restrito à distância entre as articulações $\mathrm{O}$ e B da Figura 7.

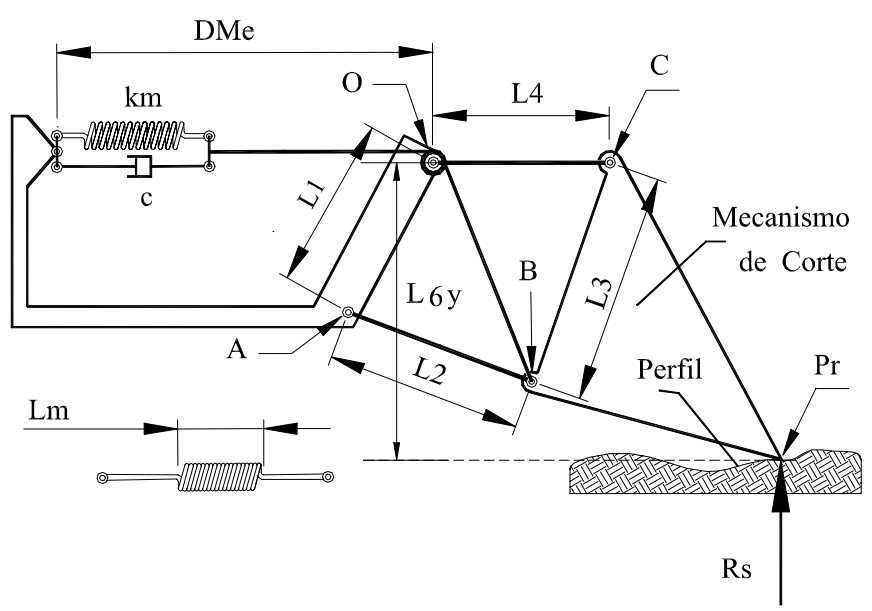

A, B, C, O - Articulações do mecanismo

L1, L2, L3 e L4 - Comprimento das barras

DMe - Comprimento de montagem externa

$\mathrm{km}, \mathrm{c}$ - Constantes elástica e de amortecimento respectivamente.

Lm - Comprimento livre da mola

Pr - Ponto de referencia do processo de seguimento

Rs - Força de interação entre perfil e mecanismo

Figura 7. Cortador basal sustentado por quatro barras

O desempenho de flutuação foi avaliado em função da continuidade do contato do mecanismo com o perfil e da magnitude da força de interação Rs entre ambos; valores nulos de Rs indicam perda de contato entre mecanismo e perfil, como pode ser observado em diversos pontos e trechos da curva experimental da Figura 8, correspondentes ao mecanismo existente, enquanto o seguimento foi satisfatório para velocidades até $2,12 \mathrm{~m} \mathrm{~s}^{-1}$, quando trafegando perfil senoidal com amplitude de $25 \mathrm{~mm}$; já o seguimento do perfil, com amplitude de $50 \mathrm{~mm}$, sofreu interrupções para velocidades superiores a $1,48 \mathrm{~m} \mathrm{~s}^{-1}$. O desempenho do mecanismo proposto por Volpato (2001) mostrou-se afetado pela altura L6y da estrutura de sustentação, o que caracteriza falta de robustez do mecanismo. Como solução para este problema, Braunbeck (2001) simulou uma configuração, denominada $\mathrm{O} 1$ em que utiliza uma mola com

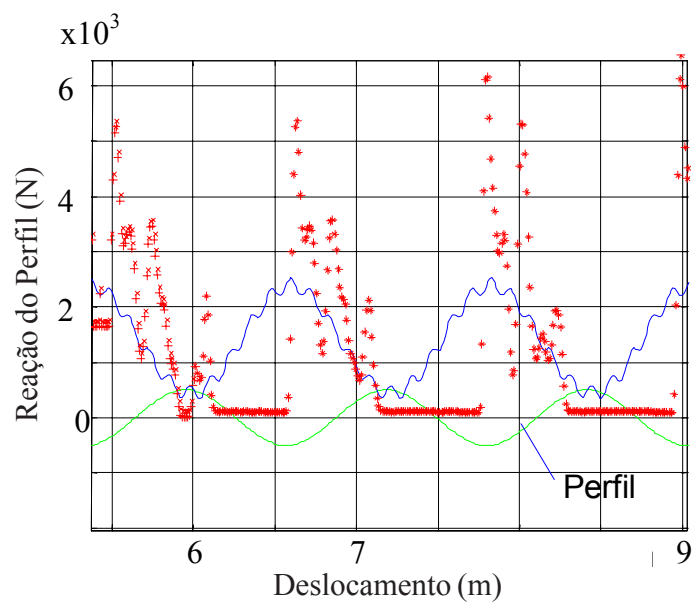

: Existente (experimental)

: Otimizado (simulado)

Ams $=50 \mathrm{~mm} ; \mathrm{Vmaq}=2,12 \mathrm{~m} \mathrm{~s}^{-1} ;$ Dme $=4,1 \mathrm{~m}$

Figura 8. Seguimento do perfil senoidal pelos mecanismos existente e otimizado baixa rigidez "km" e grande comprimento Dme $=4.400 \mathrm{~mm}$, montada fora do espaço O-B do mecanismo, como ilustra a Figura 7.

A utilização de mola, com baixa rigidez, permitiu fazer-se um ajuste na distância de montagem externa Dme, para restabelecer o contato entre o mecanismo $\mathrm{O} 1$ e o perfil, na velocidade de $2,12 \mathrm{~m} \mathrm{~s}^{-1}$. Essa distância foi reduzida para $4,1 \mathrm{~m}$ no caso mais severo do perfil, com amplitude de $50 \mathrm{~mm}$; pode-se observar, na curva simulada da Figura 8, que esta mudança promoveu continuidade do contato entre o mecanismo e o perfil, em todo o percurso, sem trechos de carga nula.

O aumento do comprimento ativo da mola, associado a uma grande redução da sua constante elástica, foi responsável pelo ganho de desempenho de seguimento e pelo aumento significativo da robustez do desempenho, com relação à altura de operação.

\section{CONCLUSÕES}

1. A existência de diversos produtos agrícolas que se apresentam, no momento da colheita, muito próximos da superfície do solo, exige um processo preciso de varredura da superfície do solo para conseguir o levantamento de corpos com dimensões normalmente pequenas.

2. O processo de varredura deve evitar que os garfos levantadores afundem no solo, já que isto provocaria contaminação do produto com sílica e bactérias do solo e, também, evitar o afastamento dos mesmos da superfície do solo, o que resultaria em perdas do produto.

3. O processo de levantamento, aplicando-se o efeito cunha, encontra-se amplamente difundido; no entanto, a precisão com que os garfos levantadores atingem o interstício solo-produto, é insuficiente na maioria dos equipamentos.

4. O posicionamento preciso do extremo inferior do garfo, no ponto de levantamento do produto, pode ser conseguido através de mecanismos ativos ou passivos, sendo que a escolha se prende fundamentalmente aos requerimentos de resposta de freqüência e ao custo de cada aplicação.

5. O ponto de referência para o controle da altura do mecanismo deve encontrar-se muito próximo do ponto de levantamento ou de corte do mecanismo.

6. Os mecanismos passivos dependem do contato direto dos mesmos com o solo, para se obter o ponto de referência requerido pelo processo de seguimento; os mecanismos ativos, não requerem, necessariamente, contato direto com o solo, se for possível adequar-se um sensor de posição para acompanhar o perfil.

7. Os mecanismos de seguimento passivos que utilizam o ponto de contato perfil-garfo como referência para o posicionamento, conseguem, se adequadamente dimensionados, seguimento contínuo do solo, com forças de interação baixas.

\section{AGRADECIMENTOS}

Os autores agradecem o apoio da FAPESP, na forma de auxílio de pesquisa e bolsas de doutoramento, para o estudo de seguimento do perfil do solo, apresentado neste artigo.

\section{LITERATURA CITADA}

Braunbeck, O.A. Redução de custos na colheita mecânica de cana-de-açúcar. Jornal da Cana, Ribeirão Preto, p.54-56, 1999. 
Braunbeck, O. A. Modelagem, simulação, otimização e construção de um cortador basal, seguidor do perfil do solo em processos de colheita. Campinas: UNICAMP. p.30, 2001. Relatório de pesquisa FAPESP: Processo 99/04745-1

Braunbeck, O.; Bauen, A.; Rosillo-Calle, F.; Cortez, L. Prospects for green cane harvesting and cane residue use in Brazil. Biomass and Bioenergy, Inglaterra, v.17, n.6, p.495-506, 1999.

EMBRAPA - Empresa Brasileira de Pesquisa Agropecuária. Centro Nacacional de Pesquisa de Arroz e Feijão. Recomendações técnicas para o cultivo do feijoeiro, Goiania, 1985. p.40. Circular No. 13

Henkel, C.R.; Fuelling, T.G.; Ridge, D.R. Effect of basecutter setting on dirt in the cane supply and cane left in the field. Proceedings of Australian Society of Sugar Cane Technologists, Mackay, v.1, 1979. p. 18-25.

Kroes, S.; Harris, H.D. Cutting forces and energy during an impact cut of sugracane stalks. CIGR Agicultural Engineering Conference, Madrid, 96A-035, 1996.

Lollato, M.A. O feijão no Paraná - Colheita, processamento e armazenamento. Londrina, PR: IAPAR, 1989. p.281-303. Circular 63

Lopes, G.T. Proposta de um controlador ótimo de altura da plataforma de corte de colhedoras. Campinas: UNICAMP, 1999. 155p. Tese Doutorado
Murcia, G.A.C. Otimização de um mecanismo articulado para o levantamento de plantas e seguimento do perfil do solo em processos de colheita. Campinas: UNICAMP, 1997.90p. Tese Doutorado.

Nunes Jr., D. Observações de Campo. Piracicaba, STAB, São Paulo, v.18, p.12-13. 2000.

Ridge, D.R. Minimizing the problem of soil in chopper harvester cane. Proceedings of the International Society of Sugarcane Technologists, Mackay, v.16, p.315-323, 1990.

Ridge, D.R.; Dick, R.G. Current research on green cane harvesting and dirt rejection by harvesters. Proceedings of Australian Society of Sugar Cane Technologists, Mackay, v.10, p.19-25, 1988.

Ridge, D.R.; Dick, R.G. Soil intake with cane during chopper harvesting: Minimising the problem. Proceedings of Australian Society of Sugar Cane Technologists, Mackay, v.14, p.25-30, 1992.

Volpato, C.E.S. Modelagem, simulação, otimização e validação experimental de um cortador de base flutuante, para seguimento do perfil do solo em colhedoras de cana-deaçúcar (Sacharum officinalis). Campinas: UNICAMP, 2001. 102p. Tese Doutorado 